\title{
Patterns and Variations in Microvascular Decompression for Trigeminal Neuralgia
}

\author{
Hiroki ToDA, ${ }^{1}$ Masanori GOTO, ${ }^{1}$ and Koichi IWASAKI ${ }^{1}$ \\ ${ }^{1}$ Department of Neurosurgery, Tazuke Kofukai Medical Research Institute and Kitano \\ Hospital, Osaka, Osaka
}

\begin{abstract}
Microvascular decompression (MVD) is a highly effective surgical treatment for trigeminal neuralgia (TN). Although there is little prospective clinical evidence, accumulated observational studies have demonstrated the benefits of MVD for refractory TN. In the current surgical practice of MVD for TN, there have been recognized patterns and variations in surgical anatomy and various decompression techniques. Here we provide a stepwise description of surgical procedures and relevant anatomical characteristics, as well as procedural options.
\end{abstract}

Key words: trigeminal neuralgia, microvascular decompression, surgical nuances

\section{Introduction}

Based on the early recognition of neurovascular compression in patients with trigeminal neuralgia (TN) by Dandy in the 1930s, ${ }^{1,2)}$ the pioneering works of Gardner and Miklos ${ }^{3)}$ and of Janneta ${ }^{4-6)}$ established microvascular decompression (MVD) as a surgical procedure during 1950-1960s. Since then, MVD has been developed to be an effective surgical treatment for TN, while various additional surgical treatments have further been pursued (Table 1). Observational studies have suggested that MVD with good pain management is beneficial, as it is the only nonablative surgical procedure available. ${ }^{7}$ The basic principle of MVD is to separate the compressing vessels from the trigeminal nerve. Most recently, studies on the use of MVD for TN treatment have focused on improving elaborate surgical techniques. The aim of this review is to describe the anatomical and surgical patterns and variations of MVD for TN. We illustrate the surgical anatomy at each step of the procedure and review various modifications of fundamental decompression techniques.

\section{Nine Surgical Steps with Relevant Surgical Anatomy}

\section{Preoperative planning}

Preoperative $\mathrm{x}$-ray, computed tomography (CT), and magnetic resonance imaging (MRI) and angiography

Received November 10, 2014; Accepted January 5, 2015
(MRA) provide morphometric information on the posterior fossa and the neurovascular structures of the trigeminal nerve. The authors routinely refer to the checklist presented in Table 2 to evaluate anatomical checkpoints as revealed by these imaging techniques; representative images are shown in Fig. 1A-F.

A detailed identification of areas indicating neurovascular compression is the most important component of the preoperative evaluation. Cisternographic heavy $\mathrm{T}_{2}$-weighted images and angiographic time-of-flight images are often merged to visualize the vessels compressing the trigeminal nerve root. Representative heavy $\mathrm{T}_{2}$ sequences include constructive interference in steady state (CISS), ${ }^{8}$ fast imaging employing steady-state acquisition (FIESTA), ${ }^{9}$ true fast inflow with steady-state precession (FISP), ${ }^{10)}$ and three-dimensional (3D) fast asymmetric spin echo (FASE). ${ }^{11)}$ In addition, 3D coronal ${ }^{12)}$ and multiplanar reconstruction (MPR) images ${ }^{13)}$ are useful for visualizing the neurovascular contacts, and the $3 \mathrm{D}$ surface-rendering virtual endoscopic view can provide clear images of the neurovascular relationship. ${ }^{14,15)}$

A meta-analysis of MRI/MRA findings from nine blinded case control studies ${ }^{16)}$ indicated that significant neurovascular contacts in the trigeminal nerve were observed more frequently with symptomatic nerves than with asymptomatic nerves (89\% vs. $36 \%)$. The accuracy of neurovascular compression findings on MRI showed high sensitivity (75-95\%) but varying specificity (26-86\%). Anatomical changes found on MRI, such as atrophy, distortion, or flattening 
Table 1 History of surgery for trigeminal neuralgia

\begin{tabular}{|c|c|c|}
\hline Year & Authors & Procedures \\
\hline 1900 & Cushing $^{56)}$ & Gasserian ganglion removal \\
\hline 1901 & Spiller, Frazier ${ }^{57)}$ & Selective subtemporal rhizotomy with sparing the motor root \\
\hline 1911 & Taptas $^{58)}$ & Alcohol injection into Meckel’s cave \\
\hline 1932 & Kirschner $^{59)}$ & Percutaneous coagulation of gasserian ganglion \\
\hline 1932 & Dandy $^{1)}$ & Posterior fossa subtotal Rhizotomy \\
\hline 1934 & Dandy $^{2)}$ & Recognition of vascular compression as a cause of neuralgia \\
\hline 1947 & Olivecrona $^{60)}$ & Subtemporal rhizotomy \\
\hline 1952 & Taarnhøj $^{61)}$ & $\begin{array}{l}\text { Intradural decompression of the gasserian ganglion and the } \\
\text { posterior root }\end{array}$ \\
\hline 1952 & Love $^{62)}$ & $\begin{array}{l}\text { Extradural decompression of the gasserian ganglion and the } \\
\text { posterior root }\end{array}$ \\
\hline 1955 & Shelden ${ }^{63)}$ & Enlarging the foramen oval and foramen rotundum \\
\hline 1959 & Gardner, Miklos ${ }^{3)}$ & First report of vascular decompression \\
\hline 1966 & Jannetta, Rand ${ }^{64)}$ & Transtentorial retrogassellian microvascular decompression \\
\hline 1971 & Jannetta ${ }^{5)}$ & Retromastoid microvascular decompression \\
\hline 1974 & Sweet, Wepsic ${ }^{65)}$ & Percutaneous radiofrequency trigeminal rhizotomy \\
\hline 1981 & Håkanson, ${ }^{66)}$ Sweet ${ }^{67)}$ & Glycerol injection rhizotomy \\
\hline 1983 & Mullan, Lichtor ${ }^{68)}$ & Balloon catheter rhizotomy \\
\hline 1993 & Rand $^{69)}$ & Gamma Knife \\
\hline 1996 & Ebel $^{70)}$ & Motor cortex stimulation for facial pain \\
\hline
\end{tabular}

Table 2 Preoperative imaging checklist

\begin{tabular}{ll}
\hline Anatomical checkpoints & Modalities \\
\hline Skull morphometry and extent of mastoid air cells & X-ray, CT, MRI \\
Surface landmarks for the junction of the transverse and sigmoid sinuses & CT \\
Presence of the subdural spaces and width of the cerebellopontine cistern & MRI \\
Position of the superior petrosal vein in the mediolateral aspect & CT, MRI \\
Identification of the vessel(s) compressing the trigeminal nerve & MRI \\
\hline
\end{tabular}

CT: computed tomography, MRI: magnetic resonance imaging.

of the trigeminal nerve, were significantly more frequently observed in symptomatic nerves (53\% vs. $9 \%$ ). The diagnostic accuracy of anatomic changes in symptomatic nerves displayed wide variation in sensitivity $(20-74 \%)$, but moderate variation in specificity $(79-100 \%)$.

\section{Anesthesia and position}

Under general anesthesia, the patient is placed in the lateral decubitus position or spine position and the eyes are taped shut after applying ointment to avoid corneal abrasion. The auditory evoked brainstem response (AEBR) is used to monitor ipsilateral hearing function. The AEBR signals are recorded from electrodes at A1/A2-Cz. Trigeminal laser-evoked potentials may be used to monitor post-surgical outcomes. ${ }^{17)}$

In our surgical practice, we use the lateral decubitus position with the head on the headrest and the contralateral arm held under the table (Fig. 2A). The trunk and head are rotated slightly away to the contralateral side (Fig. 2B). The neck is flexed slightly to improve the surgeon's visibility along the caudo-rostral direction (Fig. 2C). To allow for more convenient placing of disk electrodes for monitoring AEBR, Fz can be used instead of $\mathrm{Cz}$ without the loss of monitoring quality.

\section{Incision}

The skin incision made to expose the retromastoid area can be either linear or curved linear. In our surgical practice, we place a 6-8 $\mathrm{cm}$ linear incision 

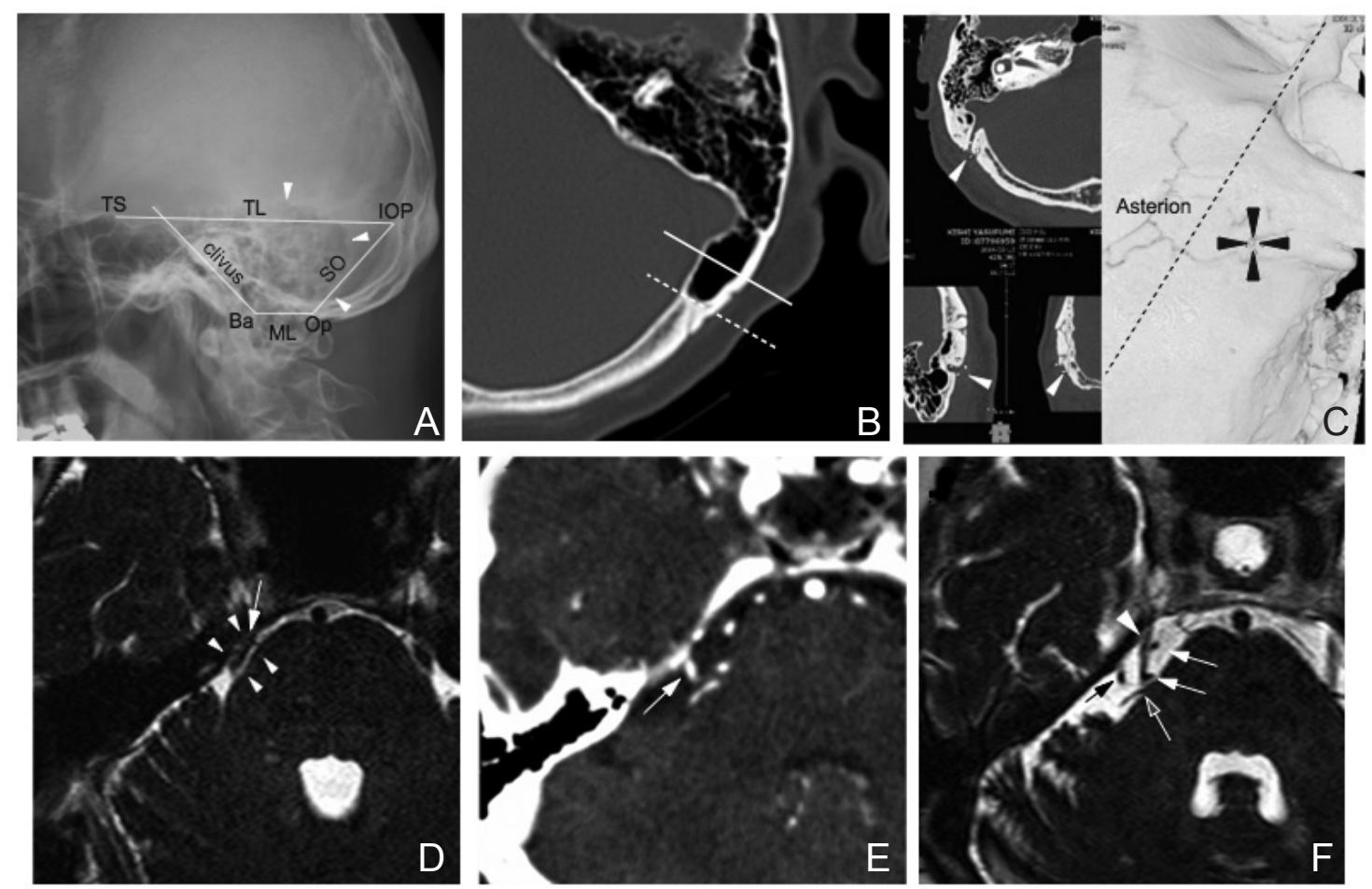

Fig. 1 Preoperative imaging. A: Lateral x-ray view shows the morphometry of the posterior fossa. Twining line (TL) from tuberculum sellar (TS) to the internal occipital protuberance (IOP), McRae line (ML) from basion (Ba) to opisthion (Op). The extent of the mastoid air cells is shown (arrowheads). B: The posterior margin of the mastoid air cells (dashed line) is posterior to the edge of the sigmoid sinus (solid line). C: Surface landmarks to identify the junction of the transverse and sigmoid sinuses and the Frankfurt plane projected onto the skull surface (dashed line) are shown. The orifice of the emissary vein is marked with triangles on the surface and multiplanar image. D: Trigeminal nerve and vascular complex (arrow) in a narrow prepontine cistern (triangles). E: Entrance of the superior petrosal vein (arrow, also in black arrow in F) into the superior petrosal sinus on contrast enhanced CT. F: Heavy $T_{2}$ images show a distorted trigeminal nerve (arrowhead) compressed with the superior loops of the cerebellar (white arrows) and anterior inferior cerebellar (open arrow) arteries. CT: computed tomography, SO: supraocciput.
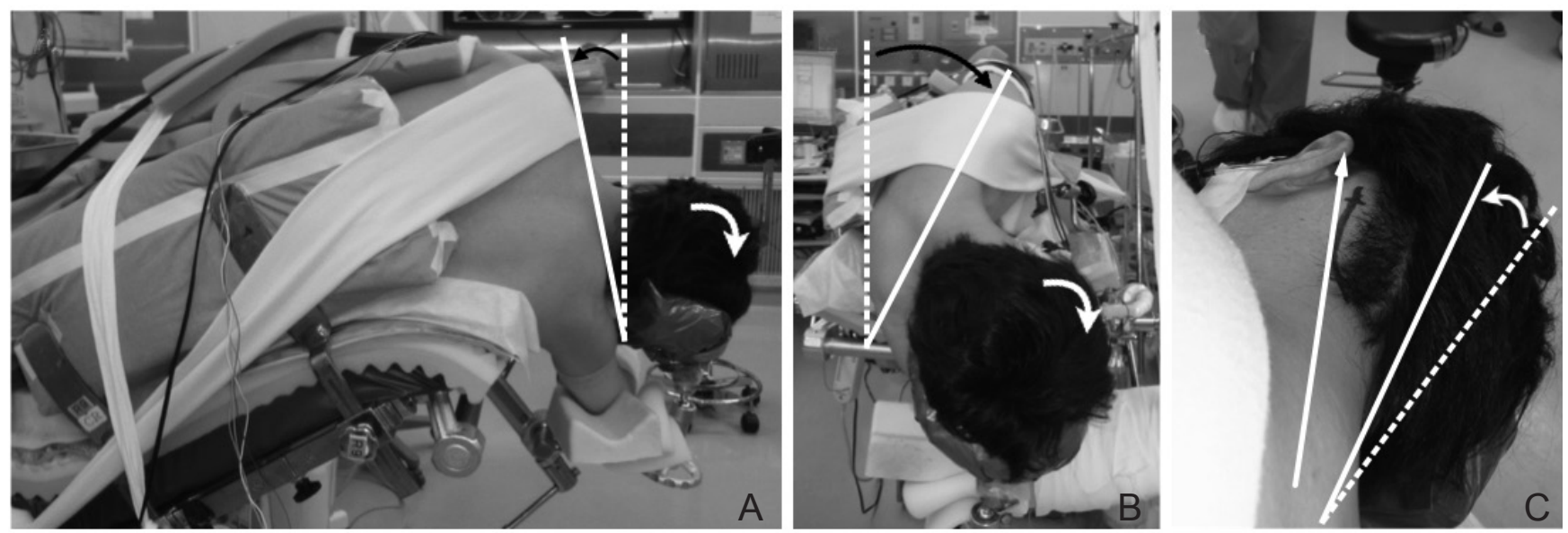

Fig. 2 Patient in a lateral recumbent position. A: The patient's shoulder is slightly retracted downward with an elastic band (solid line). The neck is slightly tilted for the vertex down position (white arrow). B: The trunk (solid line) and head are slightly rotated away (arrow) to the contralateral side. C: The neck is flexed (solid line) to allow visibility along the caudo-rostral direction (arrow). 
behind the mastoid process along the hairline (Fig. 3A). The central point of the incision is located at the mastoid notch. The incision for $\mathrm{TN}$ is placed medial and upward to the incision for hemifacial spasm, because of the differences in the operative fields and optic axes. The scalp and the underlying posterior auricular and sternocleidomastoid muscles are cut. Bleeding from the orifices of the emissary veins on the skull is controlled with minimum bone wax. Excessive bone wax may be pushed into the venous sinus. The occipital artery and other vessels in the fascia are coagulated and cut. The underlying splenius capitis, semispinalis capitis, and longissimus muscles are cut sequentially. The obliquus capitis superior muscle is detached partially in patients with a small posterior cranial fossa.

\section{Craniotomy/craniectomy}

The bone window is made by craniotomy or craniectomy to expose the borders of the transverse and sigmoid sinuses and their junction (Fig. 3B). The Frankfurt horizontal plane, asterion, mastoid tip, and orifices of the emissary veins are used as surface landmarks to predict the positions of the transverse and sigmoid junction (Fig. 1C). ${ }^{18-20)}$ The relative distances to these landmarks are variable, therefore, individualization with 3D-reconstructed CT is useful. ${ }^{21)}$

The authors prefer craniotomy to facilitate reconstruction of the bone window at closing. The direction of the perforator should be carefully controlled to avoid damaging the sinus. The mastoid air cells are sealed when they are opened to minimize fluid collection. In elderly patients, the venous sinus wall often adheres to the inner table of the occipital bone and care should be taken to avoid sinus injury. In cases of a small or tight posterior fossa, the caudal end of bone opening is widened below the inferior nuchal line.

\section{Dural opening}

The dural incision can be a U-, T-, or L-shaped cut (Fig. 3B). Bleeding from the dura is controlled with tacking sutures or minimum cauterization to avoid dural shrinkage. Bleeding near the sinuses can be controlled with oxidized cellulose and fibrin glue, as cauterization may enlarge the opening of the bleeding point.

\section{Cerebrospinal fluid (CSF) release}

After dural opening, CSF is then drained. In young patients or those with small posterior fossa, the cerebellomedullary cistern or cisterna magna is open to drain CSF. A lumbar drain is an alternative. By opening the supracerebellar and cerebellopontine cisterns, the petrotentorial junction can be observed (Fig. 3C) and the cerebellar surface is then covered with cottonoid on a rubber dam.

\section{Exposure of the superior petrosal vein, trigeminal nerve, and compressing vessels}

Further opening of the cerebellopontine cistern along the petrotentorial junction reveals the superior petrosal vein (SPV) and its tributaries (petrosal vein complex). A tapered retractor blade can be placed over the superolateral aspect of the cerebellar surface. Thorough arachnoid dissection and gravity retraction by tilting the operating table can also open the cerebellopontine angle without using a retractor blade. The arachnoid around the petrosal vein complex is dissected, while the arachnoid over the facial and auditory/vestibular nerve complex is left intact (Fig. 4A). Some experts instruct cutting of the SPV; ${ }^{4,22}$ however, it is difficult to estimate the
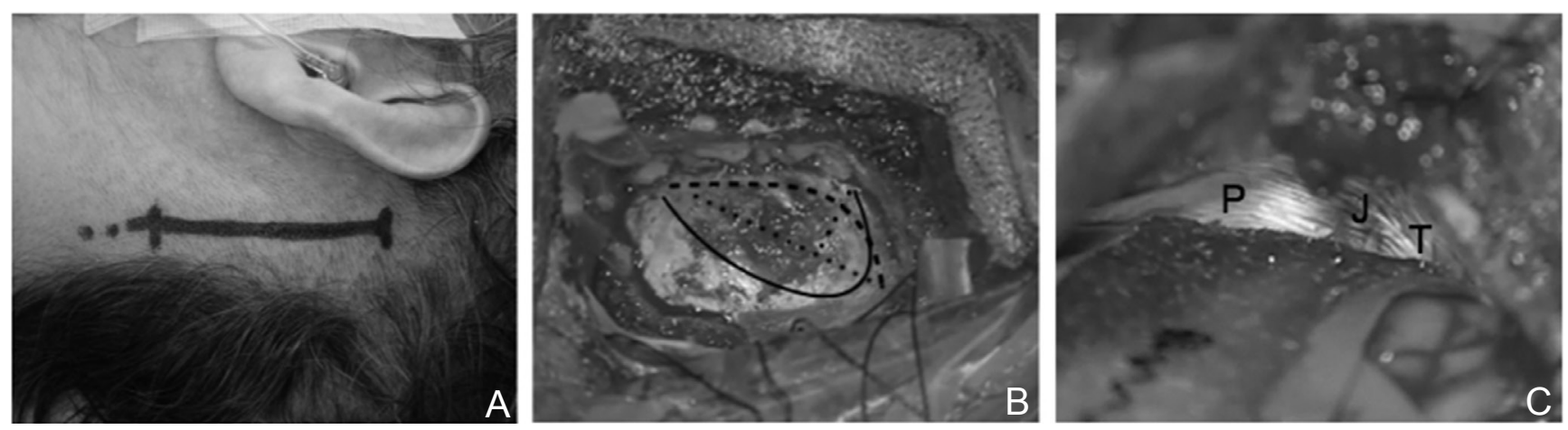

Fig. 3 Retrosigmoid approach A: A curved-linear skin incision along the hairline with minimal shaving. The midpoint of incision is placed at the superior end of the mastoid notch. B: A dural incision can be U- (solid line), T- (round dotted line), or L-shaped (dashed line) along the venous sinus. C: The first intradural landmarks are the petrous dura (P), tentorium (T), and petrotentorial junction (J). 
safety of coagulation of the SPV. Meticulous cutting of the arachnoid over the petrosal vein complex (Fig. 4B) enables us to observe the trigeminal nerve from various angles. Cutting the arachnoid over the petrosal (horizontal) fissure and superior limb of the cerebellopontine fissure (Fig. 4C) also provides wide exposure of the trigeminal nerve root (Fig. 4D). The large suprameatal tubercle ${ }^{23)}$ (Fig. 4E) is partially resected by drilling (Fig. $4 \mathrm{~F}$ ) to observe the trigeminal nerve root clearly (Fig. 4G). Complete dissection of the cerebellopontine angle near the petrotentorial junction is a key step prior to the decompression procedure.

\section{Decompression procedure}

The trigeminal nerve should be inspected from the brainstem to the Meckel's cave. As noted in Jannetta's principles ${ }^{4}$ finding the compressing vessels along the trigeminal nerve root is a surgeon's task. We must be mindful that the compressing vascular structures may include multiple vessels or a single small vein. Thorough observation of the trigeminal nerve is the most important consideration. Endoscopy may be useful for further confirmation. ${ }^{24-26)}$

Vascular decompression techniques can be classified as interposition or transposition. Simple insertion of a prosthesis between the trigeminal nerve and compressing artery should be avoided. The artery should be freed and mobilized from the original compression site before inserting the prosthesis. ${ }^{4)}$ To transpose the vessels, mobilized vessels are fixed to the tentorium or the petrous dural surface. The types of prostheses used for interpositions and various techniques of decompression are listed in Table 3.

The size and shape of the bone window and the extent of arachnoid dissection should be modified according to the type of the compressing vessels. The superior cerebellar artery (SCA), which is the most frequently observed compressing vessel, is dissected from superomedial aspects of the trigeminal nerve (Fig. 5A, B). The perforating branches from the SCA are often observed during the neurovascular dissection (Fig. 5C). Most of these perforating branches are the long circumflex type, ${ }^{27)}$ and rarely restrict mobilization. The vascular loop is separated from the trigeminal nerve (Fig. 5D) and fixed to the tentorial surface with fibrin glue (Fig. 5E, F). The anterior inferior cerebellar artery (AICA), which is the next most common compressing vessel, is dissected from caudal aspects of the trigeminal nerve. Perforating arteries from the AICA are usually short and restrict mobilization. The SPV and its draining veins
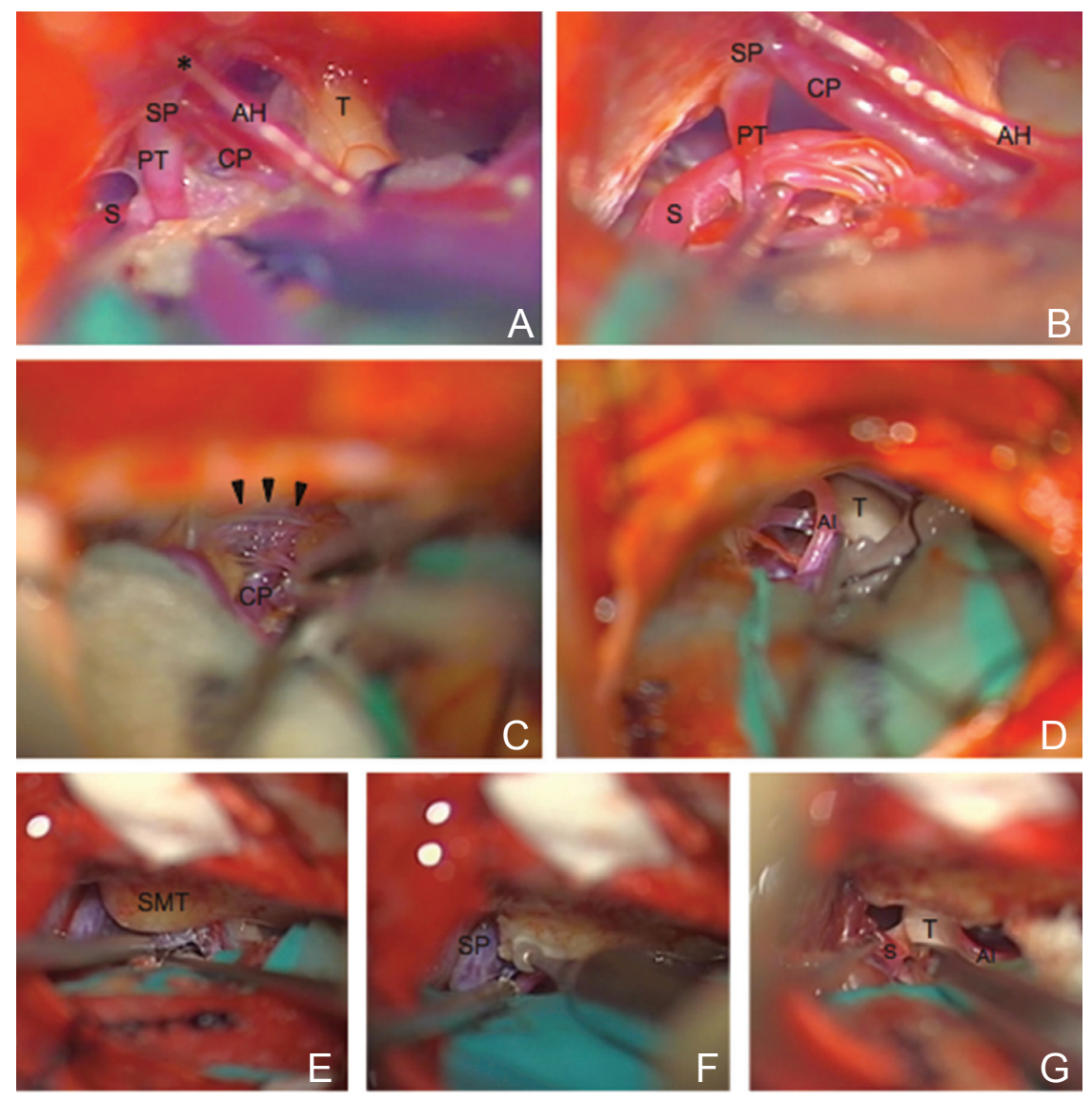

Fig. 4 Making a corridor to the trigeminal nerve root. $\mathrm{A}, \mathrm{B}$ : A right trigeminal neuralgia (TN) case. Arachnoid over the superior petrosal vein and venous complex should be dissected. Note the superior anterior hemispheric (AH) vein enters the superior petrosal sinus (asterisk) lateral to the superior petrosal (SP) vein in the illustrated case. After arachnoid dissection, the SCA is mobilized with a suction tube and microinstruments (B). C, D: A left TN case. After the arachnoid over the horizontal fissure (arrowheads) is dissected, the trigeminal nerve root and the anterior inferior cerebellar artery (AICA, AI) are observed. E-G: A right $\mathrm{TN}$ case. The dura over the suprameatal tubercle (SMT) is stripped (E) and the SMT is drilled with diamond burr (F). The trigeminal nerve root is compressed by the SCA and AICA. CP: vein of cerebellopontine fissure, PT: pontotrigeminal vein, $S$ : superior cerebellar artery (SCA), T: trigeminal nerve. 
Table 3 List of prostheses and techniques used for microvascular decompression

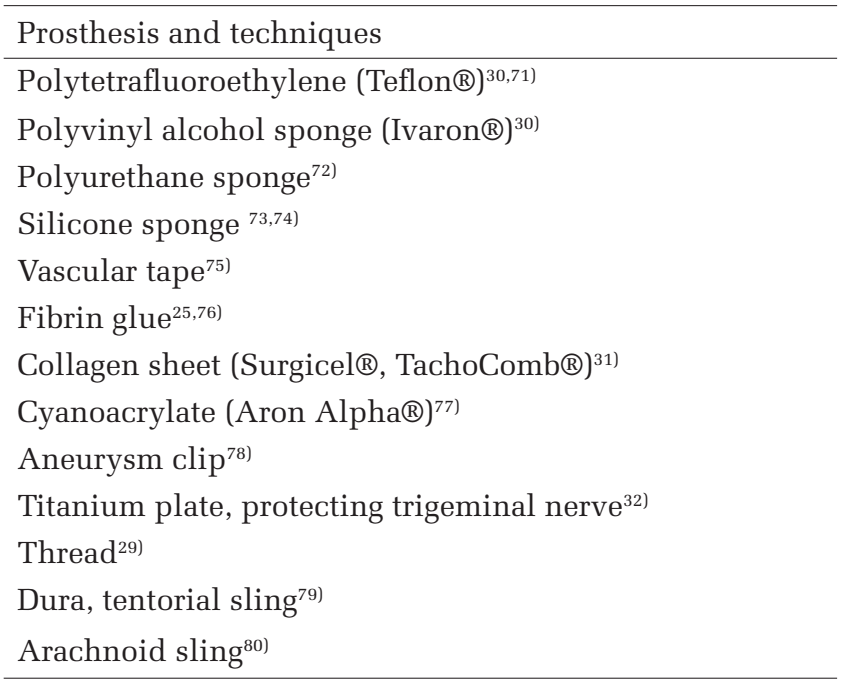

Aron Alpha®: DaiIchi Sankyo, Tokyo; Ivaron®: Ivalon Surgical Products, Eudora, KS, USA; Surgicel®: Johnson\&Johnson, Tokyo; TachoComb®: CSL Behring, Tokyo; Teflon®: Bard, Tempe, AZ, USA. sometimes compress the nerve root. Empirically, the pontotrigeminal and transverse pontine veins can be coagulated and cut due to their collateral circulation. The vertebrobasilar artery may cause TN as painful tic convulsif and other manifestations of combined hyperactive dysfunction syndrome. ${ }^{28)}$ Previous case reports have demonstrated various mobilization techniques using thread, ${ }^{29}$ tapes, ${ }^{30)}$ or adhesive glues. ${ }^{31)}$ In addition, a unique procedure using a titanium plate to protect the trigeminal nerve from the megadolicobasilar artery has been reported. ${ }^{32)}$ Arterial anomalies such as persistent primitive trigeminal artery, ${ }^{33)}$ primitive trigeminal artery variants, ${ }^{34,35)}$ and cerebellotrigeminal artery $^{36)}$ are reported to be the causes of TN. Another variation of TN is compression by the intraneural vessels. Intraneural veins ${ }^{37)}$ can be coagulated, while intraneural arteries ${ }^{38,39)}$ require wrapping, mobilization away from the original compression site, and rhizotomy. If no compressing vessel is found, then it is possible that a vascular loop may be moved away from the nerve root during CSF drainage. Such a vascular loop should be transposed and fixed to
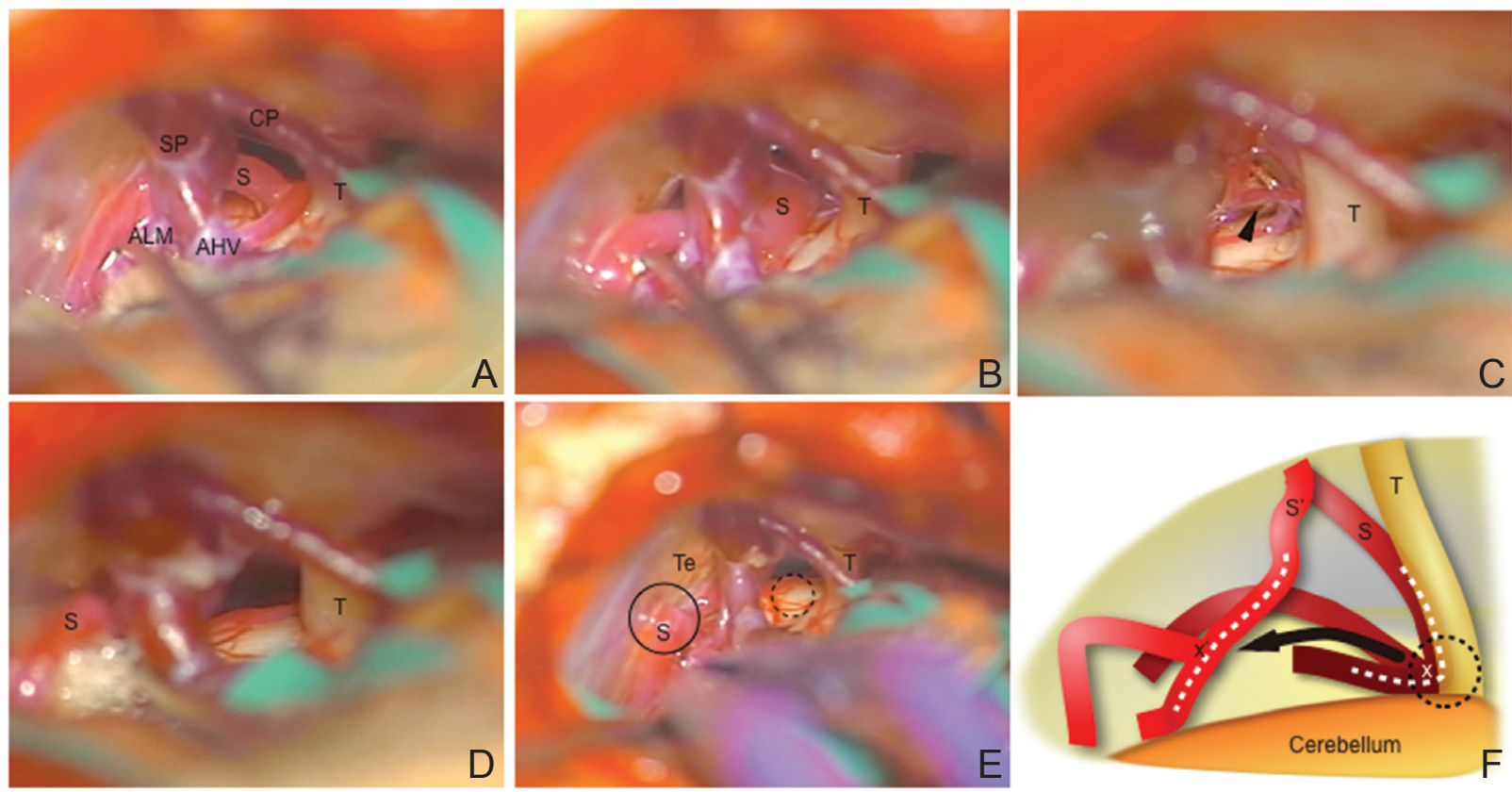

Fig. 5 Mobilization of the superior cerebellar artery (SCA) in a right trigeminal neuralgia case. A: The arachnoid around the superior petrosal (SP) vein and its tributaries has been dissected. The SCA (S) and its bifurcation compress the trigeminal nerve (T). B: The SCA is separated from the trigeminal nerve by gentle dissection around the SCA. C: Perforating arteries from the SCA (arrowhead) should be carefully dissected. D: Complete separation of vascular structure from the trigeminal nerve. E: The laterally mobilized SCA is fixed on the tentorial dura (Te) with glue (circle). Complete arachnoid dissection between the trigeminal nerve and SCA is confirmed (dashed circle). F: Illustrated scheme of vascular mobilization for the SCA loop. The SCA and its bifurcation $(\mathrm{x})$ compressing the trigeminal nerve root (dashed circle) are shown in dark red. The mobilized and transposed SCA ( $S^{\prime}$ ) with its bifurcation ( $x^{\prime}$ ) is shown in red. Lateral mobilization of the SCA (arrow) flattens the vascular loop (dashed lines) and separates the SCA from the trigeminal nerve. ALM: anterior lateral marginal vein, AHV: anterior hemispheric vein, CP: vein of cerebellopontine fissure, SCA: superior cerebellar artery. 
the dura. The surgeon also may consider rhizotomy in such cases.

In recurrent and incompletely treated cases, compression may be due to arachnoidal adhesions, previously unidentified vessels, or an interposed prosthesis, which sometimes generates granulomas. ${ }^{40)}$ Meticulous dissection of the adhesion must be carried out to avoid injury to the hidden perforating arteries. If the prosthesis is tightly adhered to the trigeminal nerve, it can be left on the surface of the nerve after removing most of the tissue. Microscissors with serrated blades are useful to cut tough synthetic fibers of some prostheses.

\section{Closure}

Before closing the dura, valsalva maneuvers are useful to confirm complete hemostasis. The dura is closed with interrupted 4-0 Nurolon sutures. Application of gelatin sponges onto the dural surface can be used to moisten the dura and help ensure a watertight closure. The bone edges of the mastoid air cells should be thoroughly waxed again. Several collagen sheets are placed over the closure line and fibrin glue is then sprayed over them. The subdural space is filled with warm artificial CSF or saline. Syringe irrigation should be used carefully with a jet of fluid to avoid tissue injury. The bone flap can be fixed with a small titanium plate and screws and bone dust collected at craniotomy is used to fill in gaps around the flap. Osteoplastic craniotomy or reconstruction of the bone window is useful to reduce wound-related complications. The fascia layers and subcutaneous tissues are approximated with interrupted absorbable sutures. The fascia closure of the superficial muscles must be watertight. The skin is closed with staples or sutures.

\section{Outcomes and Clinical Evidence}

A recent systematic review on MVD for $\mathrm{TN}^{41)}$ including 26 articles from 2000 to 2013 described a mean painfree success rate of $83.5 \%$ and complication rates of $1.3-9.1 \%$. The postoperative mortality is $0.1 \%$. Another systematic meta-analysis suggested that the most elderly patients ( $>65$ years of age) with $\mathrm{TN}$ can safely undergo MVD with excellent outcomes. ${ }^{42)}$ Outcomes are generally superior in high-volume units that see $20 \mathrm{TN}$ admissions per year and for surgeons with more than 29 annual surgical cases. ${ }^{43)}$

Practice parameters and guidelines published in 2008 by the American Academy of Neurology ${ }^{44)}$ and the European Federation of Neurological Societies ${ }^{45}$ ) also indicated that $90 \%$ of patients underwent MVD obtain pain relief. Major complications such as CSF leaks, infarcts, or hematomas are seen in $0.7-4 \%$ of patients. Aseptic meningitis occurs in $11 \%$ of patients; facial numbness in 1.3-19.6\%; and facial weakness in $0.5-6.2 \%$. Hearing loss is a major long-term complication in $0.2-3.9 \%$ or as many as $10 \%$ of patients. Incisional infection occurs in $0.1-2.5 \%$ of patients. The average mortality associated with the operation is $0.2 \%$, though rates as high as $0.5 \%$ have been reported. ${ }^{44)}$ Acute withdrawal of carbamazepine should be avoided because it causes radiographical changes in the splenium of the corpus callosum. ${ }^{46)}$ Symptom recurrence is seen in $11 \%$ of patients who resorted to repeated MVD. ${ }^{41)}$ The greatest number of recurrences occurs in the first 2 years. ${ }^{47)}$ Over $80 \%$ will remain pain-free at 1 year, $75 \%$ at 3 years, and $73 \%$ at 5 years. ${ }^{44,45)}$ Seventy percent of patients may remain pain-free without medication for up to 10 years. ${ }^{48)}$

Clinical evidence that supports the benefit of MVD for TN are limited by a lack of randomized control trials; there have been three prospective cohort studies (possible Class II) ${ }^{42,49,50)}$ and a limited number of Class III reports with independent outcomes assessment. ${ }^{48,51-54)}$ The vast majority of studies have been Class IV. The practice parameters $^{44)}$ and guidelines ${ }^{45}$ have considered surgical interventions for patients with medically refractory $\mathrm{TN}$ as Level C. The guidelines have noted that MVD may be considered over other surgical interventions because MVD provides the longest duration of pain control. Additional prospective studies on MVD for TN must be well-designed and meet high evidentiary standards. ${ }^{55}$

\section{Conclusion and Perspectives}

MVD for TN has a high success rate with low risk of morbidity and very low risk of mortality. Surgeons should be familiar with various patterns of neurovascular compressions and decompression techniques. Further studies on advanced highresolution structural and functional neuroimaging analysis, investigations directly addressing the appropriate timing of surgical interventions, and well-designed prospective trials would be useful to improve the management of $\mathrm{TN}$.

\section{Conflicts of Interest Disclosure}

The authors have declared no conflicts of interest.

\section{References}

1) Dandy WE: Concerning the cause of trigeminal neuralgia. Am J Surg 24: 447-455, 1934

2) Dandy WE: The treatment of trigeminal neuralgia by the cerebellar route. Ann Surg 96: 787, 1932 
3) Gardner WJ, Miklos MV: Response of trigeminal neuralgia to decompression of sensory root; discussion of cause of trigeminal neuralgia. J Am Med Assoc 170: 1773-1776, 1959

4) McLaughlin MR, Jannetta PJ, Clyde BL, Subach BR, Comey CH, Resnick DK: Microvascular decompression of cranial nerves: lessons learned after 4400 operations. J Neurosurg 90: 1-8, 1999

5) Jannetta PJ: Observations on the etiology of trigeminal neuralgia, hemifacial spasm, acoustic nerve dysfunction and glossopharyngeal neuralgia. Definitive microsurgical treatment and results in 117 patients. Neurochirurgia (Stuttg) 20: 145-154, 1977

6) Jannetta PJ: Arterial compression of the trigeminal nerve at the pons in patients with trigeminal neuralgia. J Neurosurg 26(Suppl): 159-162, 1967

7) Zakrzewska JM, Coakham HB: Microvascular decompression for trigeminal neuralgia: update. Curr Opin Neurol 25: 296-301, 2012

8) Yamakami I, Kobayashi E, Hirai S, Yamaura A: Preoperative assessment of trigeminal neuralgia and hemifacial spasm using constructive interference in steady state-three-dimensional Fourier transformation magnetic resonance imaging. Neurol Med Chir (Tokyo) 40: 545-555; discussion 555-556, 2000

9) Chávez GD, De Salles AA, Solberg TD, Pedroso A, Espinoza D, Villablanca P: Three-dimensional fast imaging employing steady-state acquisition magnetic resonance imaging for stereotactic radiosurgery of trigeminal neuralgia. Neurosurgery 56: E628; discussion E628, 2005

10) Meaney JF, Miles JB, Nixon TE, Whitehouse GH, Ballantyne ES, Eldridge PR: Vascular contact with the fifth cranial nerve at the pons in patients with trigeminal neuralgia: detection with 3D FISP imaging. AJR Am J Roentgenol 163: 1447-1452, 1994

11) Ishimori $T$, Nakano $S$, Kagawa M, Yokoe $K$, Togami T, Asakura H, Kusuhara T, Ohkawa M, Nagao S, Yamashita Y, Sugiura S: Virtual endoscopic images by 3D FASE cisternography for neurovascular compression. Magn Reson Med Sci 2: 145-149, 2003

12) Ohta M, Kobayashi M, Wakiya K, Takamizawa S, Niitsu M, Fujimaki T: Preoperative assessment of hemifacial spasm by the coronal heavily T2-weighted MR cisternography. Acta Neurochir (Wien) 156: 565-569, 2014

13) Yoshino $\mathrm{N}$, Akimoto $H$, Yamada $I$, Nagaoka $T$, Tetsumura A, Kurabayashi T, Honda E, Nakamura S, Sasaki T: Trigeminal neuralgia: evaluation of neuralgic manifestation and site of neurovascular compression with 3D CISS MR imaging and MR angiography. Radiology 228: 539-545, 2003

14) Tanrikulu L, Hastreiter P, Troescher-Weber R, Buchfelder M, Naraghi R: Intraoperative three-dimensional visualization in microvascular decompression. $J$ Neurosurg 107: 1137-1143, 2007

15) Takao T, Oishi M, Fukuda M, Ishida G, Sato M, Fujii Y: Three-dimensional visualization of neurovascular compression: presurgical use of virtual endoscopy created from magnetic resonance imaging. Neuro- surgery 63(1 Suppl 1): ONS139-ONS145; discussion ONS145-ONS146, 2008

16) Antonini G, Di Pasquale A, Cruccu G, Truini A, Morino S, Saltelli G, Romano A, Trasimeni G, Vanacore N, Bozzao A: Magnetic resonance imaging contribution for diagnosing symptomatic neurovascular contact in classical trigeminal neuralgia: a blinded case-control study and meta-analysis. Pain 155: 1464-1471, 2014

17) Squintani G, Turri M, Donato F, Tinazzi M, Masotto B, Tramontano V, Talacchi A, Sala F, Moretto G, Valeriani M: Trigeminal laser-evoked potentials: a neurophysiological tool to detect post-surgical outcome in trigeminovascular contact neuralgia. Eur J Pain 19: 253-259, 2015

18) Day JD, Kellogg JX, Tschabitscher M, Fukushima T: Surface and superficial surgical anatomy of the posterolateral cranial base: significance for surgical planning and approach. Neurosurgery 38: 1079-1083; discussion 1083-1084, 1996

19) Lang J, Samii A: Retrosigmoidal approach to the posterior cranial fossa. An anatomical study. Acta Neurochir (Wien) 111: 147-153, 1991

20) Tubbs RS, Cohen-Gadol AA: Landmarks for the sigmoid sinus. Neurosurgery 69: E1029; author reply E1029, 2011

21) Hamasaki T, Morioka M, Nakamura H, Yano S, Hirai T, Kuratsu J-I: A 3-dimensional computed tomographic procedure for planning retrosigmoid craniotomy. Neurosurgery 64(5 Suppl 2): 241-245; discussion 245-246, 2009

22) Cohen-Gadol AA: Microvascular decompression surgery for trigeminal neuralgia and hemifacial spasm: naunces of the technique based on experiences with 100 patients and review of the literature. Clin Neurol Neurosurg 113: 844-853, 2011

23) Shenouda EF, Coakham HB: Management of petrous endostosis in posterior fossa procedures for trigeminal neuralgia. Neurosurgery 60(2 Suppl 1): ONS63ONS69; discussion ONS69, 2007

24) Teo C, Nakaji P, Mobbs RJ: Endoscope-assisted microvascular decompression for trigeminal neuralgia: technical case report. Neurosurgery 59(4 Suppl 2): ONSE489-ONSE490; discussion ONSE490, 2006

25) Abdeen K, Kato Y, Kiya N, Yoshida K, Kanno T: Neuroendoscopy in microvascular decompression for trigeminal neuralgia and hemifacial spasm: technical note. Neurol Res 22: 522-526, 2000

26) Broggi M, Acerbi F, Ferroli P, Tringali G, Schiariti M, Broggi G: Microvascular decompression for neurovascular conflicts in the cerebello-pontine angle: which role for endoscopy? Acta Neurochir (Wien) 155: 1709-1716, 2013

27) Rhoton AL: The cerebellar arteries. Neurosurgery 47: S29-S68, 2000

28) Kobata H, Kondo A, Iwasaki K, Nishioka T: Combined hyperactive dysfunction syndrome of the cranial nerves: trigeminal neuralgia, hemifacial spasm, and glossopharyngeal neuralgia: 11-year experience and 
review. Neurosurgery 43: 1351-1361; discussion 1361-1362, 1998

29) Masuoka J, Matsushima T, Kawashima M, Nakahara Y, Funaki T, Mineta T: Stitched sling retraction technique for microvascular decompression: procedures and techniques based on an anatomical viewpoint. Neurosurg Rev 34: 373-379; discussion 379-380, 2011

30) Greenberg MS: Pain trigeminal neuralgia, in Handbook of Neurosurgery, ed 7. New York, Thieme, 2010, pp 559-562

31) Ichikawa T, Agari T, Kurozumi K, Maruo T, Satoh T, Date I: "Double-stick tape" technique for transposition of an offending vessel in microvascular decompression: technical case report. Neurosurgery 68(2 Suppl Operative): 377-382; discussion 382, 2011

32) Banczerowski P, Czigléczki G, Nyáry I: Long-term effectiveness of an ad hoc tailored titanium implant as a spacer for microvascular decompression in the treatment of trigeminal neuralgia caused by megadolichoectatic basilar artery anomaly: 9-year follow-up. J Neurosurg 121: 1492-1496, 2014

33) Park CK, Choi HJ, Lee SH, Rhee BA: Trigeminal neuralgia caused by persistent primitive trigeminal artery. J Korean Neurosurg Soc 56: 278-280, 2014

34) Morita A, Fukushima T, Miyazaki S, Shimizu T, Atsuchi M: Tic douloureux caused by primitive trigeminal artery or its variant. J Neurosurg 70: 415-419, 1989

35) Tamura Y, Shimano H, Kuroiwa T, Miki Y: Trigeminal neuralgia associated with a primitive trigeminal artery variant: case report. Neurosurgery 52: 1217-1219; discussion 1219-1220, 2003

36) Amagasaki K, Abe S, Watanabe S, Naemura K, Nakaguchi H: Trigeminal neuralgia caused by a trigeminocerebellar artery. J Neurosurg 121: 940-943, 2014

37) Helbig GM, Callahan JD, Cohen-Gadol AA: Variant intraneural vein-trigeminal nerve relationships: an observation during microvascular decompression surgery for trigeminal neuralgia. Neurosurgery 65: 958-961; discussion 961, 2009

38) Tashiro H, Kondo A, Aoyama I, Nin K, Shimotake K, Nishioka T, Ikai Y, Takahashi J: Trigeminal neuralgia caused by compression from arteries transfixing the nerve. Report of three cases. J Neurosurg 75: 783-786, 1991

39) Zheng X, Feng B, Hong W, Zhang W, Yang M, Tang Y, Zhong J, Hua X, Li S: Management of intraneural vessels during microvascular decompression surgery for trigeminal neuralgia. World Neurosurg 77: 771-774, 2012

40) Premsagar IC, Moss T, Coakham HB: Teflon-induced granuloma following treatment of trigeminal neuralgia by microvascular decompression. Report of two cases. J Neurosurg 87: 454-457, 1997

41) Xia L, Zhong J, Zhu J, Wang YN, Dou NN, Liu MX, Visocchi M, Li ST: Effectiveness and safety of microvascular decompression surgery for treat- ment of trigeminal neuralgia: a systematic review. J Craniofac Surg 25: 1413-1417, 2014

42) Sekula RF, Frederickson AM, Jannetta PJ, Quigley MR, Aziz KM, Arnone GD: Microvascular decompression for elderly patients with trigeminal neuralgia: a prospective study and systematic review with meta-analysis. J Neurosurg 114: 172-179, 2011

43) Kalkanis SN, Eskandar EN, Carter BS, Barker FG: Microvascular decompression surgery in the United States, 1996 to 2000: mortality rates, morbidity rates, and the effects of hospital and surgeon volumes. Neurosurgery 52: 1251-1261; discussion 1261-1262, 2003

44) Gronseth G, Cruccu G, Alksne J, Argoff C, Brainin M, Burchiel K, Nurmikko T, Zakrzewska JM: Practice parameter: the diagnostic evaluation and treatment of trigeminal neuralgia (an evidence-based review): report of the Quality Standards Subcommittee of the American Academy of Neurology and the European Federation of Neurological Societies. Neurology 71: 1183-1190, 2008

45) Cruccu G, Gronseth G, Alksne J, Argoff C, Brainin M, Burchiel K, Nurmikko T, Zakrzewska JM; American Academy of Neurology Society; European Federation of Neurological Society: AAN-EFNS guidelines on trigeminal neuralgia management. Eur J Neurol 15: 1013-1028, 2008

46) Honda K, Nishimiya J, Sato H, Munakata M, Kamada M, Iwamura A, Nemoto H, Sakamoto T, Yuasa T: Transient splenial lesion of the corpus callosum after acute withdrawal of antiepileptic drug: a case report. Magn Reson Med Sci 5: 211-215, 2006

47) Sarsam Z, Garcia-Fiñana M, Nurmikko TJ, Varma TR, Eldridge P: The long-term outcome of microvascular decompression for trigeminal neuralgia. Br J Neurosurg 24: 18-25, 2010

48) Zakrzewska JM, Lopez BC, Kim SE, Coakham HB: Patient reports of satisfaction after microvascular decompression and partial sensory rhizotomy for trigeminal neuralgia. Neurosurgery 56: 1304-1311; discussion 1311-1312, 2005

49) Linskey ME, Ratanatharathorn V, Peñagaricano J: A prospective cohort study of microvascular decompression and Gamma Knife surgery in patients with trigeminal neuralgia. J Neurosurg 109(Suppl): 160-172, 2008

50) Zhang H, Lei D, You C, Mao BY, Wu B, Fang Y: The long-term outcome predictors of pure microvascular decompression for primary trigeminal neuralgia. World Neurosurg 79: 756-762, 2013

51) Barker FG, Jannetta PJ, Bissonette DJ, Larkins MV, Jho HD: The long-term outcome of microvascular decompression for trigeminal neuralgia. $N$ Engl $J$ Med 334: 1077-1083, 1996

52) Broggi G, Ferroli P, Franzini A, Servello D, Dones I: Microvascular decompression for trigeminal neuralgia: comments on a series of 250 cases, including 10 patients with multiple sclerosis. J Neurol Neurosurg Psychiatry 68: 59-64, 2000 
53) Piatt JH Jr, Wilkins RH: Microvascular decompression for tic douloureux. Neurosurgery 15: 456, 1984

54) Zakrzewska JM, Thomas DG: Patient's assessment of outcome after three surgical procedures for the management of trigeminal neuralgia. Acta Neurochir (Wien) 122: 225-230, 1993

55) Zakrzewska JM, Akram H: Neurosurgical interventions for the treatment of classical trigeminal neuralgia. Cochrane Database Syst Rev 9: CD007312, 2011

56) Cushing H: Landmark article April 28, 1900: a method of total extirpation of the Gasserian ganglion for trigeminal neuralgia. By a route through the temporal fossa and beneath the middle meningeal artery. By Harvey Cushing. JAMA 250: 519-528, 1983

57) Spiller WG, Frazier CH: The division of the sensory root of the trigeminus for the relief of tic douloureux; a clinical study with a preliminary report of one surgically successful case (an experimental pathological and clinical study). Philad M J 8: 1039, 1901

58) Taptas N: Les injections d'alcool dans le ganglion de Gasser a travers le trou ovale. Presse Med 19: 798, 1911

59) Kirschner M: Zur Elektrokoagulation des Ganglion Gasseri bei Trigeminusneuralgie. Zentralbl Chir 59: 2841-2843, 1932

60) Olivecrona H: The surgery of pain. Acta Psychiatrica Scandinavica 22: 268-280, 1947

61) Taarnhøj P: Decompression of the trigeminal root and the posterior part of the ganglion as treatment in trigeminal neuralgia; preliminary communication. J Neurosurg 9: 288, 1952

62) Love JG: Decompression of the gasserian ganglion and its posterior root; a new treatment for trigeminal neuralgia; preliminary report. Proc Staff Meet Mayo Clinic 27: 257, 1952

63) Shelden CH, Pudenz RH, Freshwater DB, Crue BL: Compression rather than decompression for trigeminal neuralgia. J Neurosurg 12: 123-126, 1955

64) Jannetta PJ, Rand RW: Transtentorial retrogasserian rhizotomy in trigeminal neuralgia by microneurosurgical technique. Bull Los Angeles Neurol Soc 31: 93-99, 1966

65) Sweet WH, Wepsic JG: Controlled thermocoagulation of trigeminal ganglion and rootlets for differential destruction of pain fibers. 1. Trigeminal neuralgia. J Neurosurg 40: 143-156, 1974

66) Håkanson S: Trigeminal neuralgia treated by the injection of glycerol into the trigeminal cistern. Neurosurgery 9: 638-646, 1981

67) Sweet WH, Polelti CK, Maeon JB: Treatment of trigeminal neuralgia and other facial pains by retrogasserian injection of glycerol. Neurosurgery 9: 647-653, 1981

68) Mullan S, Lichtor T: Percutaneous microcompression of the trigeminal ganglion for trigeminal neuralgia. J Neurosurg 59: 1007-1012, 1983
69) Rand RW, Jacques DB, Melbye RW, Copcutt BG, Levenick MN, Fisher MR: Leksell Gamma Knife treatment of tic douloureux. Stereotact Funct Neurosurg 61(Suppl 1): 93-102, 1993

70) Ebel H, Rust D, Tronnier V, Böker D, Kunze S: Chronic precentral stimulation in trigeminal neuropathic pain. Acta Neurochir (Wien) 138: 1300-1306, 1996

71) McLaughlin MR, Jannetta PJ, Clyde BL, Subach BR, Comey CH, Resnick DK: Microvascular decompression of cranial nerves: lessons learned after 4400 operations. J Neurosurg 90: 1-8, 1999

72) Nagata K, Sasaki T, Basugi N: Radiopaque synthetic sponge as a prosthesis for microvascular decompression. Technical note. J Neurosurg 65: 564-565, 1986

73) Stone JL, Lichtor T, Crowell RM: Microvascular sling decompression for trigeminal neuralgia secondary to ectatic vertebrobasilar compression. Case report. J Neurosurg 79: 943-945, 1993

74) Kondo A: Follow-up results of using microvascular decompression for treatment of glossopharyngeal neuralgia. J Neurosurg 88: 221-225, 1998

75) Suzuki S, Tsuchita H, Kurokawa Y, Kitami K, Sohma T, Takeda T: New method of MVD using a vascular tape for neurovascular compression involving the vertebrobasilar artery-report of two cases. Neurol Med Chir (Tokyo) 30: 1020-1023, 1990

76) Yuyama R, Mishima K, Fujimaki T, Suzuki I, Sasaki T, Ueno H, Shibata Y, Kirino T: [Clinical experience of autologous blood transfusion and fibrin glue in neurosurgery]. No Shinkei Geka 26: 685-690, 1998 (Japanese)

77) Gandolfi A, Salvinelli F, Greco F, Casale M, D’Ascanio L: Microvascular decompression for trigeminal neuralgia: a simple and effective transposition method using synthetic adhesive. Clin Neurol Neurosurg 107: 439-440, 2005

78) Attabib N, Kaufmann AM: Use of fenestrated aneurysm clips in microvascular decompression surgery. Technical note and case series. J Neurosurg 106: 929-931, 2007

79) Melvill RL, Baxter BL: A tentorial sling in microvascular decompression for trigeminal neuralgia. Technical note. J Neurosurg 84: 127-128, 1996

80) Skrap M, Tuniz F: Use of the arachnoid membrane of the cerebellopontine angle to transpose the superior cerebellar artery in microvascular decompression for trigeminal neuralgia: technical note. Neurosurgery 66(3 Suppl Operative): ons88-ons91, 2010

Address reprint requests to: Hiroki Toda, MD, Department of Neurosurgery, Tazuke Kofukai Medical Research Institute and Kitano Hospital, 2-4-20, Ohgimachi, Kita, Osaka, Osaka 530-8480, Japan.

e-mail: htoda-nsu@umin.ac.jp 